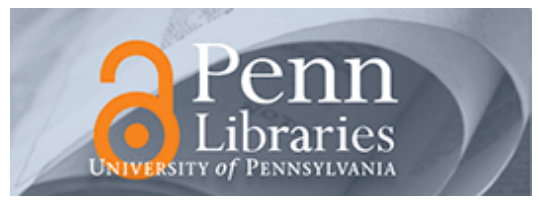

University of Pennsylvania

ScholarlyCommons

Statistics Papers

Wharton Faculty Research

$4-2008$

\title{
The Role of Rest in the NBA Home-Court Advantage
}

Oliver Entine

University of Pennsylvania

Dylan S. Small

University of Pennsylvania

Follow this and additional works at: https://repository.upenn.edu/statistics_papers

Part of the Statistics and Probability Commons

\section{Recommended Citation}

Entine, O., \& Small, D. S. (2008). The Role of Rest in the NBA Home-Court Advantage. Journal of

Quantitative Analysis in Sports, 4 (2), http://dx.doi.org/10.2202/1559-0410.1106

This paper is posted at ScholarlyCommons. https://repository.upenn.edu/statistics_papers/443

For more information, please contact repository@pobox.upenn.edu. 


\title{
The Role of Rest in the NBA Home-Court Advantage
}

\author{
Abstract \\ To date, the factors which lead to the very large home court advantage characteristic of the NBA have not \\ yet been well isolated. This study analyzes the relationship between that home court advantage and the \\ comparatively fewer days of rest between games that the NBA schedule imposes on visiting teams. A \\ statistical model has been developed and applied to the NBA data for the 2004-2005 and 2005-2006 \\ seasons to estimate the importance of the effect of rest on the magnitude of the home court advantage. \\ The results indicate that lack of rest for the road team, while not a dominant factor, is an important \\ contributor to the home court advantage in the NBA. \\ Keywords \\ home-court advantage, linear model, bootstrap \\ Disciplines \\ Statistics and Probability
}




\title{
Journal of Quantitative Analysis in Sports
}

Volume 4, Issue $2 \quad 2008 \quad$ Article 6

\section{The Role of Rest in the NBA Home-Court Advantage}

\author{
Oliver A. Entine, University of Pennsylvania
} Dylan S. Small, University of Pennsylvania

\section{Recommended Citation:}

Entine, Oliver A. and Small, Dylan S. (2008) "The Role of Rest in the NBA Home-Court Advantage," Journal of Quantitative Analysis in Sports: Vol. 4: Iss. 2, Article 6.

DOI: $10.2202 / 1559-0410.1106$

(C2008 American Statistical Association. All rights reserved. 


\title{
The Role of Rest in the NBA Home-Court Advantage
}

\author{
Oliver A. Entine and Dylan S. Small
}

\begin{abstract}
To date, the factors which lead to the very large home court advantage characteristic of the NBA have not yet been well isolated. This study analyzes the relationship between that home court advantage and the comparatively fewer days of rest between games that the NBA schedule imposes on visiting teams. A statistical model has been developed and applied to the NBA data for the 2004-2005 and 2005-2006 seasons to estimate the importance of the effect of rest on the magnitude of the home court advantage. The results indicate that lack of rest for the road team, while not a dominant factor, is an important contributor to the home court advantage in the NBA.
\end{abstract}

KEYWORDS: home-court advantage, linear model, bootstrap

Author Notes: Thanks to Gerald Entine for insightful discussion. 
Entine and Small: Role of Rest in NBA Home-Court Advantage

\section{Overview}

A fact well known to players, fans, and professional gamblers alike is that for virtually every team sport, there exists a significant home court advantage. For example, the home team wins approximately $53 \%$ of the time in major league baseball (1991-2002), 55\% of the time in the National Hockey League (1998-2003), 58\% of the time in the National Football League (2001-2005), and a dramatic $61 \%$ of the time in the National Basketball Association (2001-02 through the 2005-06 seasons). Nevertheless, despite the importance of this effect for both teams and spectators, little is understood about the root causes of this phenomenon.

Two survey articles on the home court advantage in sports are Courneya and Carron (1992), and Nevill and Holder (1999). Courney and Carron identified four factors that could account for home-court advantage: crowd factors, familiarity with local conditions, travel factors, and effects related to rule differences for the home versus visiting team. Recent studies have examined the effect of rule differences (Simon and Simonoff, 2006), the variation in the home court advantage from team-to-team (Harville, Smith, and Rubin, 1994), and how the home-court advantage accumulates over the course of a game (Jones, 2007). In this study, we consider the role of travel factors in the home-court advantage in NBA basketball.

The NBA basketball schedule favors the home teams by minimizing the number of back-to-back games that they must play and is tailored to ensure that, for the most part, the home teams play no more frequently than once every two days. In contrast, as will be shown below, the NBA schedule for the visiting teams is much more stressful, frequently requiring them to play games on successive days, which, in principle, should make them more tired than their home team opponents. Table 1 presents a comparison of the amount of rest the league gives, on average, to the home and visiting teams. As can be seen, visiting teams play more than twice as many back to back games as do the home teams. Thus, during an 82 game season, each team plays only about 11.5 back-to-back games at home, but about 27 back-to-back games while away. With this much disparity, one might conjecture that this potentially powerful factor could be a major contributor to the large home team advantage that is characteristic of the NBA.

This study analyzes all of the games for the NBA over the 2004-05 and 2005- 
Journal of Quantitative Analysis in Sports, Vol. 4 [2008], Iss. 2, Art. 6

\begin{tabular}{|ccc|}
\hline Days of Rest & Home Team & Visiting Team \\
\hline 0 & $15 \%$ & $33 \%$ \\
1 & $58 \%$ & $49 \%$ \\
2 & $19 \%$ & $13 \%$ \\
3 & $8 \%$ & $5 \%$ \\
\hline
\end{tabular}

Table 1: Distribution of Days of Rest for Home and Visiting Teams.

06 seasons, a total of 2415 games in all (excluding postseason games as well as opening games in which both teams are roughly equally rested). For these games, the home team won $60.5 \%$ of the time. Our question is, how much of this home court advantage can be attributed to the lack of rest experienced by the teams when on the road? This study will address specifically the following three questions: 1) What is the impact of rest? 2) If the distribution of road team rest was set equal to the distribution of home team rest, how much of the home court advantage would go away? And 3) Does the length of time a team has been on a road trip have an effect above and beyond its rest? In Section 2, we introduce our baseline linear model for predicting the home team's margin of victory based on the two teams' strengths and the home team's home-court advantage. In Section 3, we generalize the model slightly, and see whether or not the amount of rest affects both teams equally. Section 4 answers the question of how much of the home court advantage can be attributed to the home-team's rest, as opposed to other less tangible factors. Section 5 considers the impact of the visiting team's travel schedule, in particular, the number of consecutive games the visitors have played on their current road trip. Finally, Section 6 introduces a logistic regression framework to assess the effect the teams' respective rest has on the home team's chances of winning the game outright.

\section{The Model}

Although the home court advantage is usually described in terms of games, it can also be thought of as a factor which increases the margin of victory of the home teams when compared to that experienced by teams on the road.

DOI: $10.2202 / 1559-0410.1106$ 
Specifically, analysis of the two seasons of data shows that the average margin of victory experienced by the home teams over the visitors was 3.6 points. The analysis below is designed to determine how many, of those points, if any, arise from the lack of rest of the visiting teams.

Our starting model relates the home team's margin of victory in points to several variables. These include the strengths of each team for that given year, the home court advantage for the host team, and the amount of rest each team has coming into the game as measured by number of days off in between contests. While Harville and Smith (1994) use a random effects model to describe the individual strengths of each team, here we just consider all of the factors, including team strength, as fixed effects.

$$
\begin{gathered}
Y_{i j}=\theta_{i}-\theta_{j}+\delta_{i}+\beta_{1} * I\left[\operatorname{Rest}_{i}=0\right]+\beta_{2} * I\left[\text { Rest }_{i}=1\right]+\beta_{3} * I\left[\operatorname{Rest}_{i}=2\right] \\
-\beta_{1} * I\left[\operatorname{Rest}_{j}=0\right]-\beta_{2} * I\left[\operatorname{Rest}_{j}=1\right]-\beta_{3} * I\left[\text { Rest }_{j}=2\right]+\epsilon \\
Y_{i j}=\text { Point Margin for home team i over road team } \mathrm{j} \\
\theta_{i}=\text { Strength of home team i } \\
\theta_{j}=\text { Strength of road team } \mathrm{j} \\
\delta_{i}=\text { Home-court advantage for team i if both teams have equal rest } \\
\beta_{1}, \beta_{2}, \beta_{3}=\text { Effect of rests of zero, one, and two days respectively } \\
\text { compared to rest of three or more days. } \\
\epsilon \sim N\left(0, \sigma^{2}\right)
\end{gathered}
$$

Notice that in this particular model, there is an underlying assumption that the effect of 0,1 , or 2 days rest is the same for both the home and visiting teams, an assumption we will justify shortly. Applying this model to the data from the 2004-05 and 2005-06 seasons, we obtain the point estimates for the coefficients $\beta_{1}, \beta_{2}$, and $\beta_{3}$ shown in Table 2 .

All things being equal, a team playing a game the day immediately following another game should is expected to have a margin 1.77 points $\left(\beta_{1}\right)$ less than if that same team had more than three days of rest between contests. In contrast, playing a game after only one day off reduces the team's margin by only 0.13 points $\left(\beta_{2}\right)$ compared to if the team had three or more days off. Oddly enough, the data also indicates that a team with two days of rest actually seems to improve its scoring margin by about 0.32 points $\left(\beta_{3}\right)$. However, 
Journal of Quantitative Analysis in Sports, Vol. 4 [2008], Iss. 2, Art. 6

\begin{tabular}{|cccc|}
\hline Rest Coefficient & Estimate & SE & p-value \\
\hline$\beta_{1}$ & -1.7719 & 0.8268 & 0.0322 \\
$\beta_{2}$ & -0.1328 & 0.7924 & 0.8669 \\
$\beta_{3}$ & 0.3236 & 0.8516 & 0.7040 \\
\hline
\end{tabular}

Table 2: Point-Estimates, Standard Errors, and P-Values for the Rest Coefficients

the analysis indicates that only the $\beta_{1}$ coefficient is significant. That is, there seems to be a significant (albeit a small) detrimental effect to playing games on consecutive nights, but no evidence of further benefit of rest once the team has one or more days of rest.

\section{Does Rest Have a Different Effect for the Home and Road Teams?}

A more general model than (1) that we could use is to have different parameters for the rest coefficients of the home team versus those for the visiting team.

$$
\begin{gathered}
Y_{i j}=\theta_{i}-\theta_{j}+\delta_{i}+\beta_{1} * I\left[\operatorname{Rest}_{i}=0\right]+\beta_{2} * I\left[\operatorname{Rest}_{i}=1\right]+\beta_{3} * I\left[\operatorname{Rest}_{i}=2\right] \\
-\beta_{4} * I\left[\operatorname{Rest}_{j}=0\right]-\beta_{5} * I\left[\operatorname{Rest}_{j}=1\right]-\beta_{6} * I\left[\operatorname{Rest}_{j}=1\right]+\epsilon
\end{gathered}
$$

Does this model represent a significant improvement over (1) which has the constraints $\beta_{1}=\beta_{4}, \beta_{2}=\beta_{5}$, and $\beta_{3}=\beta_{6}$ ? Table 3 below shows a comparison of the results obtained with both the unconstrained and constrained models.

\begin{tabular}{|ccccc|}
\hline Model & Degrees of Freedom & RSS & F-Statistic & P-Value \\
\hline Unconstrained & 2291 & 281539 & 0.63997 & 0.4107 \\
Constrained & 2294 & 281774 & & \\
\hline
\end{tabular}

Table 3: Residual Sum of Squares (RSS) Comparison for Unconstrained and Constrained Model

The comparison shows that the removal of the constraints on the $\beta$ 's leaves the error sum of squares essentially unchanged, thereby indicating that the

DOI: $10.2202 / 1559-0410.1106$ 
Entine and Small: Role of Rest in NBA Home-Court Advantage

assumption that the effect of rest on performance is the same for both home and visiting teams has no appreciable impact on the results of the study. Thus, the application of this constraint to our model is appropriate.

\section{Amount of Home Court Advantage Explained by the Differences in Rest}

Over the 2004-05 and 2005-06 seasons, the overall home court advantage was roughly 3.24 points per game. What would happen though if both the home teams and the road teams had the same distribution of rest? Our model lets us answer this question. With these two distributions equal, the home court advantage would be given by $\gamma=\frac{1}{30} \sum_{i=1}^{30} \delta_{i}$ (there are 30 NBA teams). Our point estimate of $\gamma$ from model (1) is 2.93 (points per game), with a $95 \%$ CI of $(2.46,3.40)$. Thus, the different distribution of rest for the home and road teams is estimated to only account for about 0.3 points or about $10.5 \%$ of the overall home court advantage. By bootstrapping the residuals (Efron and Tibishirari, 1986), we get a $95 \%$ CI of $(5.2 \%, 17.7 \%)$ for this percent contribution.

\section{$5 \quad$ Does Length of Road Trip Matter?}

In addition to a lack of rest, a road team's overall fatigue might also be influenced by the length of a team's current road trip. A team that plays several consecutive games in opposing cities must deal with constant travel aggravation as well as jet-lag from making frequent long-distance flights over a relatively short period of time. Thus we ought to consider whether part of the NBA's home-court advantage stems not just from the days between rest, but also from the fact that the road team has spent much of its time traveling. When we include in the model an indicator variable corresponding to length of road trip, measured as number of games the visitor has played on the road since its last home game (including the current game, so that every road-trip value is at least 1), we get the following adjustments to the home court point advantage.

We estimate that there is roughly a 1-point boost for the home team when the opponent is playing its second consecutive game on the road, with a $p$-value 
Journal of Quantitative Analysis in Sports, Vol. 4 [2008], Iss. 2, Art. 6

\begin{tabular}{|cccc|}
\hline Length of Road-Trip Indicator & Estimate & SE & p-value \\
\hline 1st Game of trip & 0 & NA & NA \\
2nd Game of trip & 1.0417 & 0.5740 & 0.06968 \\
3rd Game of trip & 0.1268 & 0.7254 & 0.8612 \\
4th Game of trip or longer & -0.07701 & 0.7180 & 0.9146 \\
\hline
\end{tabular}

Table 4: Point-Estimates, Standard Errors, and P-Values for the Length of Road-trip Coefficients

of 0.07. For road trips longer than that, there is no longer much indication of a contribution of home court advantage associated with the length of such trip.

\section{Effect of Rest on Winning}

So far, we have concluded that having three or more days of rest can improve a team's score margin by as much as 1.77 points per game. However, in most NBA games, the eventual margin of victory tends to be much larger than 1 or 2 points. Thus, one might ask whether the number of days of rest variable, though significant in altering final point margins, has a significant effect on a game's final outcome (victory versus defeat). Here, we construct a model with the same variables as before, only now, we use a logistic regression framework to predict the effect of rest on the probability of a team winning the game.

DOI: $10.2202 / 1559-0410.1106$ 
Entine and Small: Role of Rest in NBA Home-Court Advantage

$$
\begin{gathered}
P\left(Y_{i j}=1\right)=\operatorname{expit}\left\{\theta_{i}-\theta_{j}+\delta_{i}+\beta_{1} * I\left[\operatorname{Rest}_{i}=0\right]+\beta_{2} * I\left[\operatorname{Rest}_{i}=1\right]\right. \\
+\beta_{3} * I\left[\operatorname{Rest}_{i}=2\right]-\beta_{1} * I\left[\operatorname{Rest}_{j}=0\right]-\beta_{2} * I\left[\operatorname{Rest}_{j}=1\right] \\
\left.-\beta_{3} * I\left[\operatorname{Rest}_{j}=2\right]\right\} \\
\text { where expit }(\mathrm{x})=\frac{e^{x}}{1+e^{x}} \\
Y_{i j}=1 \text { if home team i wins, } 0 \text { if visiting team } \mathrm{j} \text { wins } \\
\theta_{i}=\text { Strength of home team } \\
\theta_{j}=\text { Strength of away team } \\
\delta_{i}=\text { Home-court advantage for team i if both teams have equal rest } \\
\beta_{1}, \beta_{2}, \beta_{3}=\text { Effect of rests of zero, one, and two days respectively } \\
\text { compared to rest of three or more days }
\end{gathered}
$$

\begin{tabular}{|ccc|}
\hline & Estimate & $95 \%$ CI \\
\hline $\exp \left(\beta_{1}\right)$ & 0.75 & $(0.53,1.06)$ \\
$\exp \left(\beta_{2}\right)$ & 1.02 & $(0.73,1.41)$ \\
$\exp \left(\beta_{3}\right)$ & 1.14 & $(0.80,1.62)$ \\
\hline
\end{tabular}

Table 5: Point-Estimates, Standard Errors, and 95\% confidence intervals for the Length of Road-trip Coefficients in our logit model

This data indicates that playing back to back games compared to having rest of three or more days multiplies the odds of winning by $0.75\left(\beta_{1}\right)$. While not quite significant at the $5 \%$ level, this variable is significant at the $10 \%$ level, making it worthy of further consideration. $\beta_{2}$ and $\beta_{3}$ are actually slightly larger than one, which would mean that the odds of a team winning actually improve when the team has only one or two days of rest as opposed to three or more. However, neither of these coefficients are statistically significant.

\section{Conclusions}

The fact that home teams in the NBA win so large a fraction of the time is quite a fascinating observation since it implies that factors other than the skill of 
the competing teams play critical roles in the outcome of games in professional basketball. We have examined one of these factors, the travel factor, from two points of view, namely the effect of the fact that, on balance, the traveling team has a schedule which provides fewer days of rests between games, and that just being on the road an extended number of days could lead to a decrease in athletic performance. Our analysis of the 2,415 games which took place in the 2004-2005 and 2005-2006 seasons of the NBA indicates that the travel schedule does seem to be a real, although not dramatic factor contributing to the NBA's home team advantage. On average, for these two seasons, the home teams scored 3.24 more points than the visitors, of which 0.31 points arise from the smaller amount of rest that the NBA schedule provides the traveling team and 2.93 points are associated with other, non-related factors. The travel schedule effect is most clearly illustrated by the fact that visiting teams with back to back games are estimated to be 1.77 points worse off on average than visiting teams that are fully rested. The data also suggest that traveling teams score one point less during their second game on each trip, but this observation is only weakly significant.

When the issue of the home team advantage was studied with respect to the number of games won or lost, as opposed to the number of points scored, the data once again showed the importance of the tight schedule faced by the traveling teams. As with the margin of victory measured in points, the condition indicating the highest effect was when the visiting team played the second of a back to back pair of games. In this case, the odds of the visiting team winning were decreased to an estimated $75 \%$ of those corresponding to the fully rested state, although the level of significance was weak. Based on these analyses, we conclude that the extraordinary high home court advantage enjoyed by NBA teams is partially explained by the tendency of the NBA schedules for the traveling teams to have reduced rest, but that the bulk of the advantage arises from other, non-related factors.

\section{References}

Courneya, K.S. and Carron, A.V. (1992), "The Home Advantage in Sport Competitions: a Literature Review," Journal of Sport and Exercise Psychology, 14, 13-27.

Efron, B. and Tibshirani, R.J. (1986), "Bootstrap Methods for Standard Errors, Confidence Intervals, and Other Measures of Statistical Accuracy," 
Statistical Science, 1, 54-75.

Harville, D.A., Smith, M.H. and Rubin, D.R. (1994), "The Home-Court Advantage: How Large Is It and Does it Vary from Team to Team?," The American Statistician, 48, 22-29.

Jones, M.B. (2007), "Home Advantage in the NBA as a Game-Long Process," Journal of Quantitative Analysis in Sports, 3, 1-14.

Nevill, A.M. and Holder, R.L. (1999), "Home Advantage in Sport: An Overview of Studies on the Advantage of Playing at Home," Sports Med, 4, 221-236.

Simon, A.S. and Simonoff, J.S. (2006), "'Last Licks': Do They Really Help?," The American Statistician, 60, 13-18. 